\title{
The effect of body temperature on the locomotory energetics of lizards
}

\author{
Albert F. Bennett and Henry B. John-Alder \\ School of Biological Sciences, University of California, Irvine, California 92717, USA
}

Accepted May 15, 1984

Summary. 1. Oxygen consumption $\left(\dot{V}_{\mathrm{O}_{2}}\right)$, carbon dioxide production $\left(\dot{V}_{\mathrm{CO}_{2}}\right)$, and stamina were measured in the lizard Tupinambis nigropunctatus running at sustainable and non-sustainable velocities $(v)$ on a motor-driven treadmill. Three experimental groups were measured: field-fresh animals at body temperature $\left(T_{\mathrm{b}}\right)=35^{\circ} \mathrm{C}$ and laboratorymaintained animals at $T_{\mathrm{b}}=35$ and $25^{\circ} \mathrm{C}$.

2. Mean preferred $T_{\mathrm{b}}$ was determined to be $35.2{ }^{\circ} \mathrm{C}$.

3. At $35^{\circ} \mathrm{C}$, field-fresh animals had a greater maximal oxygen consumption $\left(\dot{V}_{\mathrm{O}_{2} \max }\right.$ corr $)$ (4.22 vs $3.60 \mathrm{ml} \mathrm{O}_{2} \mathrm{~g}^{-0.76} \mathrm{~h}^{-1}$ ) and a greater endurance. The net cost of transport (slope of $\dot{V}_{\mathrm{O}_{2}}$ on $v)$ did not differ between the groups $(=2.60 \mathrm{ml}$ $\left.\mathrm{O}_{2} \mathrm{~g}^{-0.76} \mathrm{~km}^{-1}\right)$. Velocity at which $\dot{V}_{\mathrm{O}_{2} \max }$ is attained (MAS) is $0.84 \mathrm{~km} \mathrm{~h}^{-1}$. The respiratory exchange ratio $(\mathrm{R})$ exceeded 1.0 at $v$ above MAS, indicating supplementary anaerobic metabolism.

4. At $25^{\circ} \mathrm{C}, \dot{V}_{\mathrm{O}_{2} \max }$ corr was lower $(2.34 \mathrm{ml}$ $\left.\mathrm{O}_{2} \mathrm{~g}^{-0.76} \mathrm{~h}^{-1}\right)$ as was endurance, MAS occurring at $0.5 \mathrm{~km} \mathrm{~h}^{-1}$. Net cost of transport was not significantly different than at $35^{\circ} \mathrm{C}$.

5. The effect of $T_{\mathrm{b}}$ on locomotory costs was analyzed for this lizard and other species. It was concluded that the net cost of transport is temperature independent in all species examined and the total cost of locomotion $\left(\dot{V}_{\mathrm{O}_{2}} v^{-1}\right)$ is temperature dependent in Tupinambis $\left(\mathrm{Q}_{10}=1.4-2.0\right)$ and all other species examined except one. The energetic cost of locomotion $\left[\left(\dot{V}_{\mathrm{O}_{2} \text { active }}-\dot{V}_{\mathrm{O}_{2} \text { rest }}\right) v^{-1}\right]$, previously reported to be temperature independent in lizards, is temperature dependent in Tupinambis $\left(Q_{10}=1.3-1.6\right)$ and in two other species.

6. Previous work has interpreted the energetic cost of locomotion as reflecting thermally indepen-

Abbreviations: $M A S$ maximal aerobic speed; $R$ respiratory exchange ratio dent costs of muscle force generation in vivo. These conclusions are questioned on both their generality and their practical and theoretical bases.

\section{Introduction}

Most metabolic rate processes are positively influenced by temperature. In ectothermic animals, both resting and maximal levels of oxygen consumption are very temperature dependent, and consequently the capacity to support activity through increased aerobic metabolism is likewise thermally dependent (Fry 1947; Brett 1964; Bennett 1978). Higher body temperatures permit greater maximal levels of oxygen consumption and greater levels of sustainable performance. However, not all aspects of locomotory costs may be similarly influenced by temperature. Recently, Rome (1982) examined the thermal dependence of the energetic cost of locomotion in the lizard Varanus exanthematicus. He concluded that this cost is temperature independent and reflects a temperature independent cost of force generation by muscles in vivo. Such thermal independence is of considerable interest for both its physiological and energetic implications. The purpose of this study is to examine the generality of the observation that energetic costs of locomotion in lizards are temperature independent. The locomotory energetics of the lizard Tupinambis nigropunctatus are analyzed and compared to those of other species reported in the literature.

Tupinambis nigropunctatus is a large (approximately $1 \mathrm{~kg}$ ) teiid lizard, one of several species of the genus, which is widely distributed through South America. Tupinambis is superficially similar 
to lizards of the genus Varanus, and historically there has been some confusion between the genera (Mertens 1942). It is now known that they belong to very distantly related families, which are members of different infraorders. Although the respiratory physiology of Tupinambis has received some attention (e.g., Perry and Duncker 1978; Klemm et al. 1979; Glass et al. 1981), very little is known about its energetics or ecology. This study examined the effect of body temperature $\left(T_{\mathrm{b}}\right)$ on resting and active metabolic rate and endurance capacity. We also examined the effect of long-term laboratory maintenance on these factors. As there is no thermal information published on this species, preferred $T_{\mathbf{b}}$ was measured to permit analysis of locomotory energetics at environmentally realistic temperatures.

\section{Materials and methods}

Animal supply and maintenance. Six Tupinambis nigropunctatus were purchased from a commercial animal dealer, who arranged for their collection and direct importation from Guyana. The animals were maintained individually in pens approximately $1 \mathrm{~m}^{3}$ in volume, equipped with incandescent lights set on a $12 \mathrm{~h}$ day, $12 \mathrm{~h}$ night photo- and thermal-period. Animals were fed live mice regularly and had continuous access to drinking water. The animals grew and remained in good health over several years.

Preferred body temperature. Behaviorally-regulated body temperature was measured in a thermal gradient. The gradient consisted of an open-topped box approximately $3 \mathrm{~m}$ in length, $0.75 \mathrm{~m}$ in width, and $1 \mathrm{~m}$ in height. Its floor was covered with sand and a General Electric radiant heater connected to a variable transformer was mounted above one end of the gradient. Even light intensity over the gradient surface was provided by overhead fluorescent bulbs. Sand surface temperatures in the gradient ranged from 21 to $41^{\circ} \mathrm{C}$. One animal (fasted two days prior to measurement) was placed in the gradient at a time. Each lizard was fitted with a cloacal thermocouple and placed in the gradient on the night before its temperature determination. Body temperature during the photophase was measured with a Honeywell model 16 multipoint recorder. After an initial warming period of several hours, the lizards maintained a stable temperature until shortly before the scotophase. Measurements of body temperature during only this stable portion of the thermoregulatory cycle were individually averaged for each lizard.

Locomotory energetics. Oxygen consumption $\left(\dot{V}_{\mathrm{O}_{2}}\right)$ and carbon dioxide production $\left(\dot{V}_{\mathrm{CO}_{2}}\right)$ were measured while the lizards walked on a motor-driven treadmill. The measurements were made over a range of velocities $(v)$, but each determination was made while the lizard walked at a single velocity. Three different sets of measurements were made:

Exp. 1) $T_{\mathrm{b}}=35^{\circ} \mathrm{C}$, measurement shortly after animals were obtained from the field (mean mass $=865 \mathrm{~g}$ ).

Exp. 2) $T_{\mathrm{b}}=35^{\circ} \mathrm{C}$, measurement after animals were held captive for 12-15 months (mean mass $=1,089 \mathrm{~g}$ ).

Exp. 3) $T_{b}=25^{\circ} \mathrm{C}$, measurement after $24+$ months of captivity (mean mass $=988 \mathrm{~g}$ ).

Animals were fasted at least 2 days prior to measurement and were walked only once a week. An animal was placed in a temperature-controlled cabinet overnight. In the morning the lizard was fitted with a cloacal thermistor and a lightweight, clear mask. Preliminary experimentation indicated that these lizards could not be induced to walk immediately after being masked. Consequently the masked animal was put in a loose cotton bag on the tread surface and left undisturbed for 1-2 $\mathrm{h}$ prior to activity, while air was drawn through the mask with a down-stream diaphragm pump. The animal was then removed and induced to walk on the treadmill by tapping on the tail and hind limbs. Tread speed was set between 0.2 and $2.0 \mathrm{~km} \mathrm{~h}^{-1}$. At lower speeds, the lizards walked for at least $30 \mathrm{~min}$ and runs were terminated after that time. At faster speeds, they walked for shorter periods and fell from the end of the tread exhausted. The time of sustained activity was recorded. Only those runs in which the lizard maintained position in the treadmill and matched locomotion to tread speed are reported.

Gas exchange measurements were made on air excurrent from the mask. Air was drawn through the mask by a diaphragm pump via a length of Tygon tubing, a column of silica gel to remove water vapor, and a Brooks model 5841 flow controller and a rotameter. Air flow was regulated at $2.01 \mathrm{~min}^{-1}$. A sample (approximately $500 \mathrm{ml} \mathrm{min}^{-1}$ ) of the flow was drawn through a column of indicating calcium sulfate and into an Applied Electrochemistry model S3A oxygen analyzer and a Beckman model LB-2 carbon dioxide analyzer with a downstream diaphragm pump. The gas analyzers were connected to a Honeywell dual pen flatbed recorder. The analyzers were calibrated with gases of known composition prior to each run. Air flow through the mask was sufficient to capture all expired gases (verified by decreasing flow rate and measuring equal levels of $\dot{V}_{\mathrm{O}_{2}}$ ). Excurrent gas composition never exceeded $1 \% \mathrm{CO}_{2}$ nor fell below $20 \% \mathrm{O}_{2} . T_{\mathrm{b}}$ of the animals was maintained at 25.0 or $35.0^{\circ} \mathrm{C} \pm 1.0^{\circ} \mathrm{C}$ with a Versa-Therm model 2158 temperature controller to which the cloacal thermistor was connected. The heating circuit of the latter activated a General Electric radiant heater suspended above the treadmill. Body temperature was measured frequently with a Yellow Springs Instrument model 46 TUC telethermometer. $\dot{V}_{\mathrm{O}_{2}}$ and $\dot{V}_{\mathrm{CO}_{2}}$ were calculated according to Eqns. (1) and (2) of Gleeson (1979a). Resting, pre-active measurements were made during the $15 \mathrm{~min}$ period prior to activity and were recorded only if there had been no prior struggling activity. Gas exchange during sustained activity was determined for a 5 min period relatively late in the run, during which oxygen consumption was lowest and most stable. At $2 \mathrm{~km} \mathrm{~h}^{-1}, 2$ min periods were used. Chart records were planimetered over these periods to obtain average values of excurrent gas composition. All results are reported at STPD conditions

\section{Results}

\section{Preferred body temperature}

The mean preferred $T_{\mathbf{b}}$ during the stable, postwarming period was $35.2{ }^{\circ} \mathrm{C} \pm 0.56 \mathrm{SE}(n=6)$. Individual mean values ranged from 33.5 to $36.8^{\circ} \mathrm{C}$.

\section{Locomotory energetics}

$\dot{V}_{\mathrm{O}_{2}}$ of active animals for all three experimental groups is reported in Fig. 1. Resting oxygen consumption averaged $0.043 \mathrm{ml}_{2} \quad \mathrm{~g}^{-1} \quad \mathrm{~h}^{-1} \pm$ 


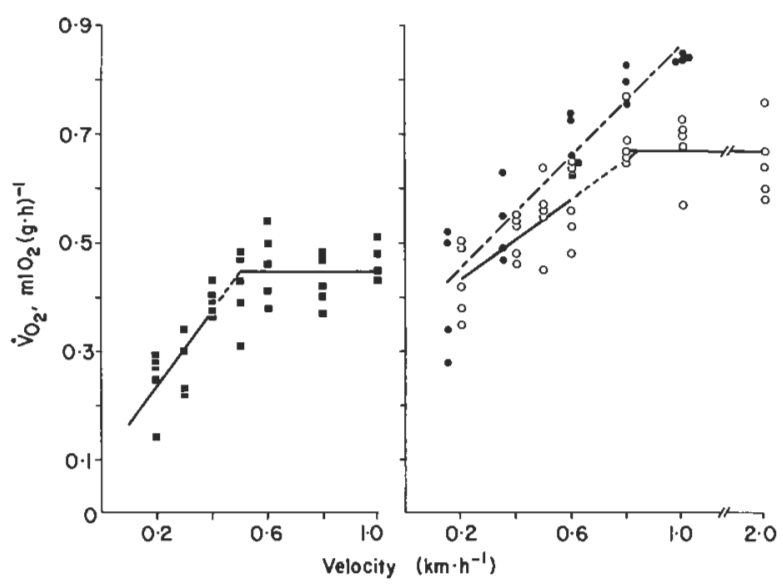

Fig. 1. Oxygen consumption at different running speeds. Left: $T_{\mathrm{b}}=25^{\circ} \mathrm{C}$ (closed squares). Right: $T_{\mathrm{b}}=35^{\circ} \mathrm{C}$, field-fresh animals (closed circles and dashed regression line, Exp. 1) and laboratory-maintained animals (open circles and solid regression line, Exp. 2). Regression equations and their method of calculation are reported in the text

$0.0058 \mathrm{SE}(n=27)$ at $25^{\circ} \mathrm{C}$ and $0.136 \mathrm{ml} \mathrm{O}_{2} \mathrm{~g}^{-1}$ $\mathrm{h}^{-1} \pm 0.0067 \mathrm{SE}(n=22)$ at $35^{\circ} \mathrm{C}$.

A single linear regression was calculated to describe the dependence of oxygen consumption on velocity for field-fresh animals with $T_{\mathrm{b}}=35^{\circ} \mathrm{C}$ (Exp. 1):

$$
\dot{V}_{\mathrm{O}_{2}}=0.348+0.521 v\left(n=20, \mathrm{r}^{2}=0.85, p<0.001\right)
$$

where $\dot{V}_{\mathrm{O}_{2}}$ is $\mathrm{ml} \mathrm{O}_{2} \mathrm{~g}^{-1} \mathrm{~h}^{-1}$ and $v$ is velocity in $\mathrm{km} \mathrm{h}^{-1}$ (range $=0.15$ to $1.0 \mathrm{~km} \mathrm{~h}^{-1}$ ). $\dot{V}_{\mathrm{O}_{2}}$ at $1.0 \mathrm{~km} \mathrm{~h}^{-1} \quad$ averaged $\quad 0.842 \mathrm{ml}^{-} \quad \mathrm{O}_{2} \mathrm{~g}^{-1} \mathrm{~h}^{-1} \pm$ $0.0021 \mathrm{SE}(n=4)$. The slope of this relationship $\left(0.521 \mathrm{ml} \mathrm{O}_{2} \mathrm{~g}^{-1} \mathrm{~km}^{-1}\right)$ is the net cost of transport.

The data for laboratory-maintained animals with $T_{\mathrm{b}}=35^{\circ} \mathrm{C}$ (Exp. 2) are clearly not linear over the observed velocity range. For such data, we followed the method of John-Alder and Bennett (1981), which calculates all possible pairs of linear regressions by dividing the data into two ranges of velocity. The pair of linear equations that resulted in the least total residual sums of squares is as follows:

$$
\dot{V}_{\mathrm{O}_{2}}=0.357+0.373 v\left(n=20, \mathrm{r}^{2}=0.49, p<0.001\right)
$$

over the velocity range 0.2 to $0.6 \mathrm{~km} \mathrm{~h}^{-1}$, and

$$
\dot{V}_{\mathrm{O}_{2}}=0.713-0.032 v\left(n=15, \mathrm{r}^{2}=0.09, p=0.29\right)
$$

over the velocity range of 0.8 to $2.0 \mathrm{~km} \mathrm{~h}^{-1}$. The latter is not a significant regression, and the average value of oxygen consumption over this velocity

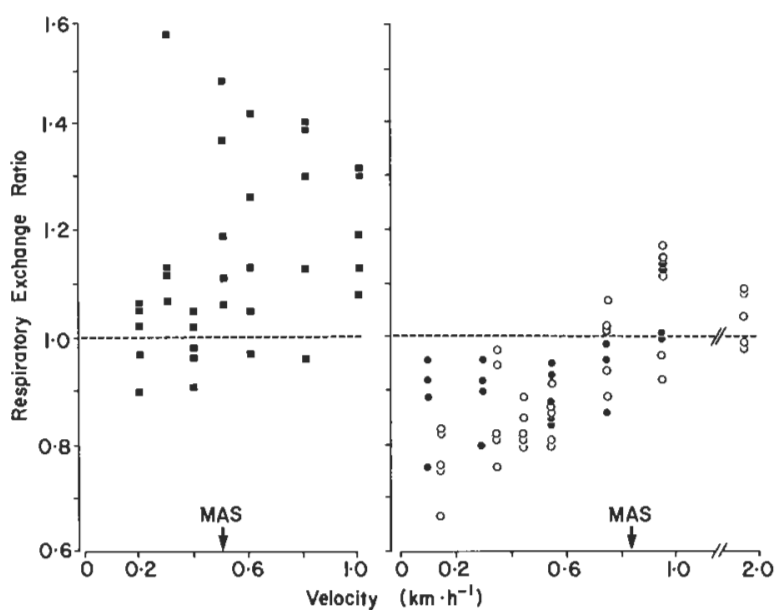

Fig. 2. Respiratory exchange ratios at different running speeds. Left: $T_{\mathrm{b}}=25^{\circ} \mathrm{C}$. Right: $T_{\mathrm{b}}=35^{\circ} \mathrm{C}$. Symbols as in Fig. 1 . MAS indicates maximal aerobic speeds (defined in text)

range $\left[=\right.$ maximal oxygen consumption $\left.\left(\dot{V}_{\mathrm{O}_{2} \max }\right)\right]$ is $0.672 \mathrm{ml} \mathrm{O}_{2} \mathrm{~g}^{-1} \mathrm{~h}^{-1} \pm 0.0153 \mathrm{SE}(n=15)$. These data sets intersect at $0.84 \mathrm{~km} \mathrm{~h}^{-1}$, the maximal aerobic speed (MAS), the predicted velocity at which $\dot{V}_{\mathrm{O}_{2} \max }$ is attained (John-Alder and Bennett 1981).

Data for laboratory-maintained animals with $T_{\mathrm{b}}=25^{\circ} \mathrm{C}($ Exp. 3) are likewise non-linear, and the pair of regressions with the lowest total residual sums of squares is

$\dot{V}_{\mathrm{O}_{2}}=0.090+0.716 v\left(n=14, \mathrm{r}^{2}=0.61, p=0.001\right)$

over the range 0.2 to $0.4 \mathrm{~km} \mathrm{~h}^{-1}$, and

$\dot{V}_{\mathrm{O}_{2}}=0.367+0.110 v\left(n=20, \mathrm{r}^{2}=0.11, p=0.14\right)$

over the range 0.5 to $1.0 \mathrm{~km} \mathrm{~h}^{-1}$. Equation 5 is not a significant regression and oxygen consumption over this range $\left(\dot{V}_{\mathrm{O}_{2} \max }\right)$ averages $0.447 \mathrm{ml} \mathrm{O}_{2} \mathrm{~g}^{-1} \mathrm{~h}^{-1} \pm 0.0145 \mathrm{SE}^{2}(n=20)$. These data sets coincide at $0.50 \mathrm{~km} \mathrm{~h}^{-1}$, the MAS at this temperature.

Respiratory exchange ratios $(\mathrm{R})$ of resting animals were $0.81( \pm 0.048 \mathrm{SE}, n=27)$ at $25^{\circ} \mathrm{C}$ and $0.68( \pm 0.020 \mathrm{SE}, n=22)$ at $35^{\circ} \mathrm{C}$. These values increased during activity (Fig. 2). At $25^{\circ} \mathrm{C}$, R measured at velocities below MAS averaged 1.06 $( \pm 0.043 \mathrm{SE}, n=14)$; at velocities at or greater than MAS, R averaged $1.21( \pm 0.035 \mathrm{SE}, n=20)$. At $35^{\circ} \mathrm{C}$, below MAS, R averaged $0.87( \pm 0.013 \mathrm{SE}$, $n=41)$ and, above MAS, averaged 1.06 $( \pm 0.022 \mathrm{SE}, n=14)$. This increment is significant at both $25^{\circ} \mathrm{C}(p=0.01$ by Student's $t$ test $)$ and 


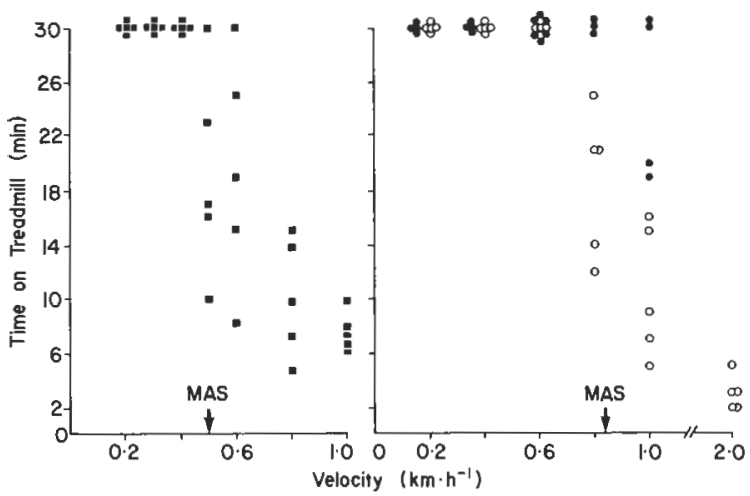

Fig. 3. Time sustained on tread. Left: $T_{\mathrm{b}}=25^{\circ} \mathrm{C}$. Right: $T_{\mathrm{b}}=$ $35^{\circ} \mathrm{C}$. Symbols as in Fig. 1. MAS indicates maximal aerobic speed. Experiments were terminated after $30 \mathrm{~min}$ of running

$35^{\circ} \mathrm{C}(p<0.001)$. $\mathrm{R}$ values measured below MAS were not significantly greater than 1.0 at either $T_{\mathrm{b}}(p>0.1$ by one-tailed Student's $t$ test) and those measured at or above MAS were significantly above 1.0 at both $T_{\mathrm{b}}$ 's $(p<0.01)$. Values of $\mathrm{R}$ in excess of 1.0 during activity are indicative of supplementary anaerobic metabolism (Gleeson and Bennett 1982).

Walking times on the treadmill are given in Fig. 3. Field-fresh animals at $35^{\circ} \mathrm{C}$ (Exp. 1) were all able to sustain $0.8 \mathrm{~km} \mathrm{~h}^{-1}$ and half sustained $1.0 \mathrm{~km} \mathrm{~h}^{-1}$ for over $30 \mathrm{~min}$. Laboratory-maintained animals at $35^{\circ} \mathrm{C}$ (Exp. 2) sustained $0.6 \mathrm{~km} \mathrm{~h}^{-1}$ but all exhausted within $30 \mathrm{~min}$ at $0.8 \mathrm{~km} \mathrm{~h}^{-1}$. Laboratory-maintained animals at $25^{\circ} \mathrm{C}$ (Exp. 3) sustained $0.4 \mathrm{~km} \mathrm{~h}^{-1}$, but endurance declined at $0.5 \mathrm{~km} \mathrm{~h}^{-1}$. The coincidence of MAS, the velocity at which $\dot{V}_{\mathrm{O}_{2} \text { max }}$ is attained, with maximum sustainable velocity has been observed for all lizards so far examined (Cnemidophorus, Bennett and Gleeson 1979; Dipsosaurus, JohnAlder and Bennett 1981; Heloderma, John-Alder et al. 1983; Iguana, Moberly 1968; Gleeson et al. 1980; Varanus, Gleeson et al. 1980; Gleeson 1981).

\section{Effect of laboratory maintenance}

Did laboratory maintenance affect locomotor capacity and aerobic energetics in these animals? Performance may be compared at $T_{\mathrm{b}}=35^{\circ} \mathrm{C}$ for fieldfresh animals (Exp. 1) and animals maintained for over a year under laboratory conditions (Exp. 2). These experimental groups differed significantly in body mass and this factor is known to influence both resting and maximal mass-specific levels of oxygen consumption in reptiles (Bennett 1982). Therefore, a mass correction of $b=0.76$ (from Bennett 1982, for active lizards at $35^{\circ} \mathrm{C}$ ) is applied to all data before comparison. Mass-corrected maximal oxygen consumption $\left(\dot{V}_{\mathrm{O}_{2} \max \text { corr }}\right)$ declined during laboratory maintenance. For animals in Exp. $1, \dot{V}_{\mathrm{O}_{2} \max }$ corr was significantly greater (4.22 $\mathrm{ml} \mathrm{O}_{2} \mathrm{~g}^{-0.76} \mathrm{~h}^{-1} \pm 0.075 \mathrm{SE}, n=4$ ) than for animals during Exp. $2\left(\dot{V}_{\mathrm{O}_{2} \max \text { corr }}=3.60 \mathrm{ml} \mathrm{O}\right.$ $\mathrm{g}^{-0.76} \mathrm{~h}^{-1} \pm 0.080 \mathrm{SE}, n=15$ ) (Student's $t=3.81$, d.f. $=17$, two tailed $p=0.02$ ). These differences in $\dot{V}_{\mathrm{O}_{2} \max \text { corr }}$ are reflected in differences in endurance and maximal aerobic speed. Exp 1 animals had greater stamina at both 0.8 and $1.0 \mathrm{~km} \mathrm{~h}^{-1}$ than did Exp. 2 animals.

The net cost of transport (the velocity-dependence of oxygen consumption) was not affected by laboratory maintenance. Mass-corrected values of oxygen consumption $\left(\mathrm{ml} \mathrm{O}_{2} \mathrm{~g}^{-0.76} \mathrm{~h}^{-1}\right)$ for Exps. 1 and 2 were compared by multiple regression analysis with dummy variables and analysis of covariance to test for differences in slope and elevation between data sets (Kleinbaum and Kupper 1978). Neither slopes ( $F=1.48$; d.f. $=1.36 ; p=$ $0.23)$ nor mean-adjusted elevations of the data sets $(\mathrm{F}=1.49$; d.f. $=1.37 ; p=0.23)$ are significantly different. These data sets are pooled to give the following regression:

$\dot{V}_{\mathrm{O}_{2} \text { corr }}=1.71+2.60 v\left(n=40, \mathrm{r}^{2}=0.80, p<0.001\right)$

where $\dot{V}_{\mathrm{O}_{2} \text { corr }}$ is given in $\mathrm{ml} \mathrm{O}_{2} \mathrm{~g}^{-0.76} \mathrm{~h}^{-1}$.

\section{Effect of body temperature}

The effect of $T_{\mathrm{b}}$ on locomotory energetics is analyzed by comparing laboratory-maintained animals at $25^{\circ} \mathrm{C}$ (Exp. 3) with those at $35^{\circ} \mathrm{C}$ (Exp. 2). For comparison, all metabolic values are adjusted to $\operatorname{mass}^{0.76}$, as these groups differ in body mass. $\dot{V}_{\mathrm{O}_{2} \max }$ corr at $25^{\circ} \mathrm{C} \quad$ (Exp. 3) is $2.34 \mathrm{ml} \mathrm{O}_{2} \mathrm{~g}^{-0.76} \mathrm{~h}^{-1} \pm 0.077 \mathrm{SE}(n=20)$ and is significantly lower than that at $35^{\circ} \mathrm{C}$ (Student's $t=11.17$, d.f. $=33, p<0.001)$. The temperature coefficient $\left(\mathrm{Q}_{10}\right)$ for $\dot{V}_{\mathrm{O}_{2} \text { max corr }}$ between 25 and $35^{\circ} \mathrm{C}$ is 1.54. MAS is $0.50 \mathrm{~km} \mathrm{~h}^{-1}$ at $25^{\circ} \mathrm{C}$ and $0.84 \mathrm{~km} \mathrm{~h}^{-1}$ at $35^{\circ} \mathrm{C}\left(\mathrm{Q}_{10}=1.68\right)$, and endurance shows a similar thermal dependence (Fig. 3).

The net cost of transport is not significantly affected by temperature. The data described by Eqns. (2) and (4) were compared, after correction for mass differences, by multiple regression analysis with dummy variables and analysis of covariance. Slope (the net cost of transport) is not significantly different between the two groups $(\mathrm{F}=2.78$, d.f. $=1.30 ; p=0.10)$. Mean adjusted elevations of the data sets are significantly different $(F=53.5$; 
d.f. $=1.31 ; p<0.001)$ and mass-corrected equations for locomotory costs for $T_{\mathrm{b}}=35^{\circ} \mathrm{C}$ (Exp. 2) and $T_{\mathrm{b}}=25^{\circ} \mathrm{C}(\operatorname{Exp} .3)$ are, respectively:

$\dot{V}_{\mathrm{O}_{2} \text { corr }}=1.78+2.31 v$

and

$\dot{V}_{\mathrm{O}_{2} \text { corr }}=0.90+2.31 v$

where $\dot{V}_{\mathrm{O}_{2} \text { corr }}$ is in $\mathrm{ml} \mathrm{O}_{2} \mathrm{~g}^{-0.76} \mathrm{~h}^{-1}$.

\section{Discussion}

There are numerous ways of expressing the energetic costs associated with locomotory activity. In the current literature, there are three different terms that have been frequently employed to describe energetics of terrestrial locomotion: 1) the net cost of transport, 2) the total cost of locomotion, and 3) the energetic cost of transport. While all three of these can be expressed in similar units (e.g., $\mathrm{ml} \mathrm{O}_{2} \mathrm{~g}^{-1} \mathrm{~km}^{-1}$ ), they measure distinctly different aspects of locomotory energetics. The following discussion will examine the thermal dependence of each of these costs in the six species of lizards for which they have been measured: Dipsosaurus dorsalis (John-Alder and Bennett 1981), Heloderma suspectum (John-Alder et al. 1983), Iguana iquana (Moberly 1968), Tupinambis nigropunctatus (this study), Uromastix aegyptius (Dmi'el and Rappeport 1976), and Varanus exanthematicus (Rome 1982).

Net cost of transport - the slope of the curve relating oxygen consumption to velocity (SchmidtNielsen 1972) (= minimum cost of running, Taylor et al. 1970). This is the most common expression currently in use. It subtracts the 'Y-intercept' quantity (the extrapolated value of $\dot{V}_{\mathrm{O}_{2}}$ at zero velocity) from observed $\dot{V}_{\mathrm{O}}$ and isolates the effect of increasing velocity alone on energetic costs. It is velocity independent. This slope is temperature independent in Tupinambis (Eqns. 7 and 8) and in all other lizards examined: Dipsosaurus, Heloderma, and Iguana, and in Uromastix over the temperature range for which similar posture is maintained. Data for Varanus were not gathered over a range of velocities that is broad enough to permit analysis.

Total cost of locomotion - oxygen consumption divided by velocity (Schmidt-Nielsen 1972) $(=\mathrm{cost}$ of transport, Tucker 1970). This value measures the organismal energetic input to activity and includes both maintenance and 'postural' costs as well as those associated with locomotion per se. It is velocity-dependent and decreases with increasing speed, as these non-locomotory portions of the

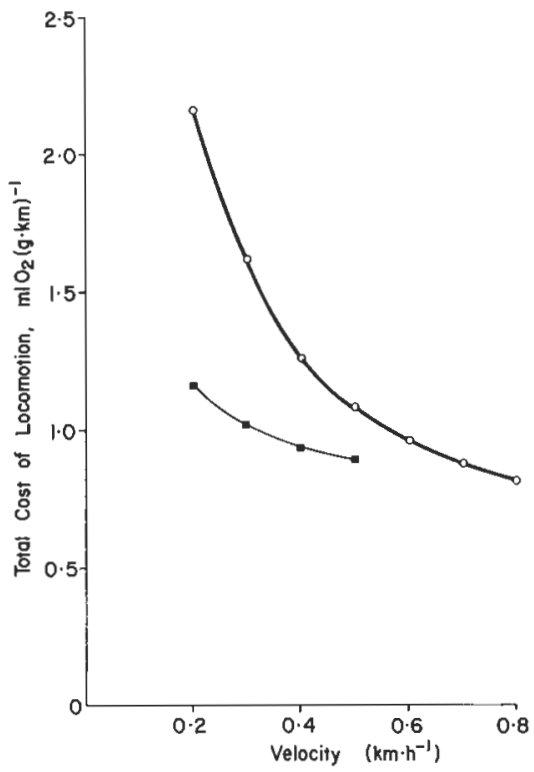

Fig. 4. Total cost of locomotion at $T_{\mathrm{b}}=25^{\circ} \mathrm{C}$ (closed squares) and $T_{\mathrm{b}}=35^{\circ} \mathrm{C}$ (open circles). Points calculated from Eqns. 2 and 4

total cost become relatively less important at greater velocities. These costs are shown for Tupinambis in Fig. 4. At any sustainable velocity, the total cost of locomotion is greater at the higher $T_{\mathrm{b}}$, with $\mathrm{Q}_{10}$ 's ranging from 1.4 to 2.0 , depending on speed. The total cost of locomotion is temperature dependent in most other lizards examined: Dipsosaurus $\left(\mathrm{Q}_{10}\right.$ range $\left.=1.3-1.9\right)$, Heloderma (1.2-1.6), Iguana (1.2-1.3), and Varanus (1.1-1.2). Only in Uromastix has it been reported to be independent of $T_{\mathrm{b}}$, i.e. that the lizard has the same $\dot{V}_{\mathrm{O}_{2}}$ walking at a given speed regardless of $T_{\mathrm{b}}$.

Energetic cost of locomotion - the difference between active and resting oxygen consumption divided by speed (Rome 1982) (=energetic cost of walking, metabolic cost of activity, Moberly 1968). This expression describes excess costs (both 'postural' and locomotory) associated with locomotion above resting levels. This is the quantity Rome (1982) determined to be temperature independent in Varanus and that he associated with in vivo force generation by the locomotory muscles. Such a thermal independence would suggest that locomotion at a given speed entails a set metabolic cost that is additive to maintenance requirements. As Rome pointed out, a fixed metabolic increment is in contrast to most other metabolic processes, which are thermally dependent, including those associated with the cost of force production by muscle in vitro $\left(Q_{10} \simeq 3\right.$, Rome and Kushmerick 1983).

Is this thermal independence of the energetic 
cost of locomotion a general feature of saurian locomotory energetics? A similar independence was reported for Iguana (Moberly 1968), but these data are less than completely satisfactory as no primary data are reported, post-active rather than resting values were subtracted from active values, and no statistical treatment of the results is given. This differential between active and pre-active resting values (mass-corrected) was analyzed for individual Tupinambis at $25^{\circ} \mathrm{C}$ (Exp. 3) and $35^{\circ} \mathrm{C}$ (Exp. 2). Multiple regression analysis with dummy variables and analysis of covariance indicates no significant difference between slopes of the data sets $(=$ net cost of transport) $(\mathrm{F}=3.84$; d.f. $=1.20$; $p=0.06)$ and a significant temperature effect (elevation $)(\mathrm{F}=9.60 ;$ d.f. $=1.21 ; p=0.006)$. The regression equations describing these energetic costs are

$\dot{V}_{\mathrm{O}_{2} \text { corr }}=1.22+1.83 v$

and

$\dot{V}_{\mathrm{O}_{2} \text { corr }}=0.78+1.83 \mathrm{v}$

at $35^{\circ} \mathrm{C}$ and $25^{\circ} \mathrm{C}$, respectively $\left(\dot{\mathrm{V}}_{\mathrm{O}_{2} \text { corr }}\right.$ in $\left.\mathrm{ml} \mathrm{O}_{2} \mathrm{~g}^{-0.76} \mathrm{~h}^{-1}\right)$. The $\mathrm{Q}_{10}$ values of these relationships range from 1.3 to 1.6 , depending on velocity. The energetic cost is also temperature dependent in Dipsosaurus, with $\mathrm{Q}_{10}$ 's ranging from 1.3 to 2.1 . In Uromastix, there is apparently a negative influence of $T_{\mathrm{b}}$ on energetic cost of locomotion, as total cost of locomotion is temperature independent and resting metabolic rate is positively temperature dependent. As resting metabolic rate was not reported for Heloderma, no similar determination can be made for this species. Consequently, for five species examined, energetic cost of locomotion is reported to be independent of temperature in two, positively temperature dependent in two, and negatively temperature dependent in one.

In summary, the thermal dependence of locomotory costs in lizards is complex, but some generalizations can be made. The net cost of transport is temperature independent in all species examined. The total cost of locomotion is nearly always temperature dependent (five of six species), but with a fairly low $Q_{10}(1.1-2.0)$ in comparison to most other energetic processes. The thermal dependence of the energetic cost of locomotion appears to vary considerably among species, increasing, decreasing, or remaining unaffected with changes in $T_{\mathrm{b}}$. Its thermal independence is not a general property of the locomotory energetics of lizards.

The measurement of the energetic cost of locomotion presents several difficulties, particularly if temperature is an experimental variable. Metabolic rate measured prior to activity will vary with the length of the rest period, amount and type of prior activity associated with capturing and masking, struggling during the equilibration period, and several other factors. There is no reason to assume these will be similar at different $T_{\mathrm{b}}$ 's. Observed pre-active metabolic rate is not standard metabolic rate, which is taken to reflect true minimal maintenance requirements (Bennett and Dawson 1976). As it departs from minimal values, there can be pronounced effects on the apparent thermal dependence of the differential between it and active metabolic rate. These may reflect no more than differential recovery from prior activity at different $T_{\mathrm{b}}$ 's. Perhaps some of the diversity in thermal responses reported for different species results from such effects. The net cost of transport and the total cost of locomotion are not subject to this sort of error, as they depend only on observed $\dot{V}_{\mathrm{O}_{2}}$ measured during defined levels of activity.

There are also interpretive problems associated with the energetic cost of locomotion, particularly as a quantitative measure of the force generation capacity of muscle (e.g., Rome 1982). This difficulty arises from the unknown disposition of 'maintenance processes' during activity. Measurement of the differential between resting and active metabolic rates implicitly assumes that the former remain constant during activity and their energetic contribution can be accounted for. As the functional components of resting metabolic rate are little understood, there is no particular support for this assumption. What is clear is that some processes associated with oxygen transport and delivery are augmented during activity (e.g., ventilatory and cardiovascular work) and themselves represent a portion of the increased levels of oxygen consumption associated with activity. The disposition of energy expenditure for other functions may presumably increase or decrease. Consequently, an unknown portion of the energetic cost of locomotion as so defined is not related to muscle contractile energetics and force generation. There is no a priori reason to assume that this unknown fraction is constant at different $T_{\mathrm{b}}$ 's. Given this uncertainty, the utilization of the energetic cost of locomotion to estimate in vivo muscle energetics does not appear to be a promising approach.

Tupinambis is not a lizard of exceptional aerobic capacity or stamina. MAS at $T_{\mathrm{b}}=35^{\circ} \mathrm{C}$ is similar to that previously reported for Amblyrhynchus (Gleeson 1979a), Dipsosaurus (John-Alder and Bennett 1981), Heloderma (John-Alder et al. 1983), and Uromastix (Dmi'el and Rappeport 1976). Its 
$\dot{V}_{\mathrm{O}_{2} \max }$ (measured in Exp. 1) is $46 \%$ above that predicted for lizards at $35^{\circ} \mathrm{C}$ (Bennett 1982), but is similar, after correction for differences in mass, to that of numerous other lizards (e.g., Amblyrynchus, Dipsosaurus, Heloderma, Iguana - data summarized in Gleeson 1981, and John-Alder et al. 1983). $\dot{V}_{\mathrm{O}_{2} \max \text { corr }}$ in Tupinambis appears substantially lower than that reported for Varamus exanthematicus (Gleeson et al. 1980; Rome 1982) and $V$. salvator (Gleeson 1981), but similar to that of $V$. gouldii (Bennett 1972). At its selected $T_{\mathrm{b}}$, the net cost of transport is only $57 \%$ (Exp. 2) to $75 \%$ (Exp. 1) of that predicted for lizards (Gleeson 1979a, Eqn. 4). The cost is similar to that previously reported $\left(0.35 \mathrm{ml} \mathrm{O}_{2} \mathrm{~g}^{-1} \mathrm{~km}^{-1}\right)$ for a 1,200 g Tupinambis of unspecified $T_{\mathrm{b}}$ (Bakker 1972).

Long-term laboratory maintenance in these experiments was associated with a decline in $\dot{V}_{\mathrm{O}_{2} \max }$ of approximately $15 \%$ and a concomitant decline in MAS and endurance. These decrements are probably the result of relative inactivity of cagemaintained animals. Net cost of transport was not significantly affected. It is possible that some other factors (e.g., season of measurement, John-Alder, in press) were also involved in these differences. The only other study (Gleeson 1979b) examining training and/or maintenance effects in lizards found no change in $\dot{V}_{\mathrm{O}_{2} \max }$ or performance after 6-8 weeks of training or inactivity. The results of the present study, however, suggest a cautious approach to the interpretation of data concerning maximal capacities for performance and oxygen transport in animals held captive for long periods of time.

Acknowledgements. We thank James Stearns for assistance in collecting data. Financial support was provided by NSF Grants PCM 77-24208, 81-02331, and NIH Grant K04-AM00351.

\section{References}

Bakker RT (1972) Locomotor energetics of lizards and mammals compared. Physiologist 15:76

Bennett AF (1972) The effect of activity on oxygen consumption, oxygen debt, and heart rate in the lizards Varanus gouldii and Sauromahs hispidus. J Comp Physiol $79: 259-280$

Bennett AF (1978) Activity metabolism of the lower vertebrates. Annu Rev Physiol 40:447-469

Bennett AF (1982) The energetics of reptilian activity. In: Gans C, Pough FH (eds) Biology of the reptilia, vol 13. Academic Press, New York, pp 155-199

Bennett AF, Dawson WR (1976) Metabolism. In: Gans C, Pough FH (eds) Biology of the reptilia, vol 5. Academic Press, New York, pp 127-223
Bennett AF, Gleeson TT (1979) Metabolic expenditure and the cost of foraging in the lizard Cnemidophorus murinus. Copeia 1979:573-577

Brett JR (1964) The respiratory metabolism and swimming performance of young sockeye salmon. J Fish Res Bd Canada $21: 1183-1226$

Dmi'el R, Rappeport D (1976) Effect of temperature on metabolism during running in the lizard Uromastix aegyptius. Physiol Zool 49:77-84

Fry FEJ (1947) Effects of the environment on animal activity. Pub Ont Fish Res Lab $68: 1-62$

Glass ML, Johansen K, Abe AS (1981) Pulmonary diffusing capacity in reptiles: Relations to temperature and oxygen uptake. J Comp Physiol 142:509-514

Gleeson TT (1979a) Foraging and transport costs in the Galapagos marine iguana, Amblyrhynchus cristatus. Physiol Zool $52: 549-557$

Gleeson TT (1979b) The effects of training and captivity on the metabolic capacity of the lizard Sceloporus occidentalis. J Comp Physiol 129:123-128

Gleeson TT (1981) Preferred body temperature, aerobic scope, and activity capacity in the monitor lizard, Varanus salvator. Physiol Zool 54:423-429

Gleeson TT, Bennett AF (1982) Acid-base imbalance in lizards during activity and recovery. J Exp Biol 98:439-453

Gleeson TT, Mitchell GS, Bennett AF (1980) Cardiovascular responses to graded activity in the lizards Varanus and Iguana. Am J Physiol (Reg Integ Comp Physiol) 8: R174R179

John-Alder HB (1984) Seasonal variation in activity, aerobic energetic capacities, and plasma thyroid hormones (T3 and T4) in an iguanid lizard. J Comp Physiol B 154:409-420

John-Alder HB, Bennett AF (1981) Thermal dependence of endurance and locomotory energetics in a lizard. Am J Physiol 241 (Reg Integ Comp Physiol 10): R342-R349

John-Alder HB, Lowe CH, Bennett AF (1983) Thermal dependence of locomotory energetics and aerobic capacity of the gila monster (Heloderma suspectum). J Comp Physiol $151: 119-126$

Kleinbaum DG, Kupper LL (1978) Applied Regression Analysis and Other Multivariable Methods. Duxbury Press, North Scituate, Massachusetts

Klemm RD, Gatz RN, Westfall JA, Fedde MR (1979) Microanatomy of the lung parenchyma of a tegu lizard Tupinambis nigropunctatus. J Morphol $161: 257-280$

Mertens R (1942) Die Familie der Warane (Varanidae). I. Allgemeines. Abh Senckenberg Naturforsch Ges 462:1-116

Moberly WR (1968) The metabolic responses of the common iguana, Iguana iguana, to walking and diving. Comp Biochem Physiol 27:21-32

Perry SF, Duncker HR (1978) Lung architecture, volume, and static mechanics in 5 species of lizards. Respir Physiol $34: 61-82$

Rome LC (1982) Energetic cost of running with different muscle temperatures in savannah monitor lizards. J Exp Biol 99: 269-277

Rome LC, Kuchmerick MJ (1983) Energetics of isometric contractions as a function of muscle temperature. Am J Physiol 244 (Cell Physiol 13): C100-C109

Schmidt-Nielsen K (1972) Locomotion: Energy cost of swimming, flying, and running. Science 177:222-228

Taylor CR, Schmidt-Nielsen K, Raab JL (1970) Scaling of energetic cost of running to body size in mammals. Am J Physiol 219:1104-1107

Tucker VA (1970) Energetic cost of locomotion in animals. Comp Biochem Physiol 34:841-846 